\title{
SURGERY CAN BE AVOIDED IN EXTRA OCULAR AND ORBITAL MYOCYSTICERCOSIS
}

\section{Corresponding Author:}

\section{Dr. Mohammed Ather}

Professor of Ophthalmology, Gandhi Medical College, Musheerabad, India Incharge Department of Oculoplasty SD eye Hospital, Telangana State India

Email id: ather11258@gmail.com

\section{Co-Authors:}

\section{P Padmavathi}

Assistant Professor of Ophthalmology, Sarojini Devi Eye Hospital, Hyderabad TS, India

\section{Padma Prabha}

Assistant Professor of Ophthalmology, Sarojini Devi Eye Hospital, Hyderabad TS, India

\section{Mirza Mohammed Mohiuddin Baig}

Assistant Professor of Ophthalmology, Sarojini Devi Eye Hospital, Hyderabad, TS, India

\section{Nasreen}

Assistant Professor of Pharmacology, Osmania Medical College, Hyderabad, TS, India

\section{Pallavi Gupta}

Junior Resident, Sarojini Devi Eye Hospital, Hyderabad, TS, India

\begin{abstract}
:
Aim: To study the efficacy of Albendazole in treating Extra ocular and Orbital Myocysticercosis.

Materials and Methods: This is a prospective interventional case study conducted at Department of Oculoplasty and Orbital disorder of Sarojini Devi Eye Hospital which is a tertiary care eye hospital. 6 cases of Myocysticercosis, 4 males and 2 females presented between Jan 2014 to June 2014 at department of Oculoplasty were included in the study. After clinical examination and radiological confirmation patients were given oral Albendazole 400mg BD for 3 weeks along with Tab. Prednisolone $1 \mathrm{mg}$ $/ \mathrm{Kg}$ of body weight. They were evaluated clinically for control of symptoms like pain, redness and protrusion of eyeball and regression of signs like reduction in chemosis, Proptosis and tenderness.

Results: All 6 cases responded to medical treatment by Albendazole and Prednisolone by total reduction in symptoms and signs thereby avoiding surgery on them.

Conclusion: Ocular and Orbital Myocysticercosis respond well to medical treatment by Tab. Albendazole along with Tab. Prednisolone.

Key Words: Myocysticercosis, Albendazole, Proptosis, Prednisolone.
\end{abstract}

\section{INTRODUCTION:}

Myocysticercosis is caused by a Cysticercus cellulosae, the larval form of helminth, tape worm Taenia solium and taenia saginata. It is contracted by (a) Ingestion of infective cysticerci in under cooked pork or beef. (b) Ingestion of eggs of t. solium and t. saginata in contaminated water, food and vegetables. (c) Regurgitation of eggs from the small intestine into stomach $^{1}$.
It affects the skeletal muscles, Blood vessels, CNS and potential spaces in the body. In eyes, it effects vitreous cavity, sub retinal space, Choroid, Extra ocular muscles, LPS, Sub conjunctival space in the form of cysts.

It is unanimously accepted that intra ocular cyst should be removed surgically. Extra ocular and Orbital myocysticercosis can be treated successfully by medical means. 
Aim: to study the efficacy of Albendazole and Prednisolone for treating Extra ocular and Orbital cysticercosis.

\section{MATERIALS AND METHODS:}

This is a prospective interventional case study conducted at the Department of Oculoplasty and Orbital diseases of Sarojini Devi Eye hospital. 6 cases of Myocysticercosis 4 males 2 females presented at our hospital between Jan 2014 and June 2014 were included in the study. Informed consent obtained from them. Cases were clinically examined by an experienced Ophthalmologist using Slit lamp, Indirect Ophthalmoscope, B scan ultrasonography. The diagnosis is made clinically and supported by Ultra sonography and CT scan of Orbit Axial and coronal view which delineate the scolex in the cyst. Of the 6 cases 3 males and a female had cyst in LPS-Superior rectus complex producing Ptosis, Proptosis, Chemosis of conjunctiva and limitation of elevation of globe. 1 male and a female patient had cyct in Medial rectus causing Eccentric proptosis, Chemosis of Conjunctiva and limitation of adduction. All the 6 cases were given Tab. Albendazole $400 \mathrm{mg}$ bd along with tab. Prednisolone $1 \mathrm{mg} / \mathrm{Kg}$ body weight for a period of 3 weeks.

\section{RESULTS:}

All cases responded to treatment by regression in symptoms like pain, protrusion of eyeball and redness. There was marked reduction in Proptosis, chemosis, improvement in Ptosis and Extra ocular muscle action.

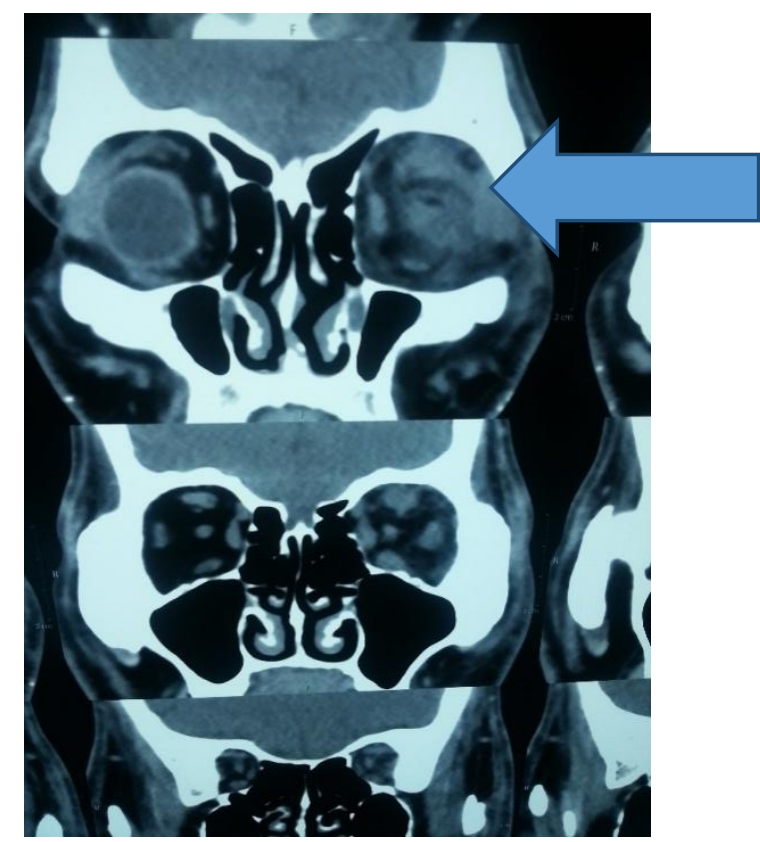

Figure 1: Coronal cut of CT scan showing Scolex in LPS Superior rectus complex

\section{DISCUSSION:}

The result noted in our study is consistent with the studies conducted elsewhere. Murthy GR et al treated Sub conjunctival cyst by Albendazole which showed regression ${ }^{2}$. Rath $\mathrm{S}$ et al and R. Shihota \& Honavar et al showed similar results while treating extra ocular and orbital myocysticercosis ${ }^{3,4}$. Puri P and Grover AK et al in double blind study showed same results ${ }^{5}$. Mehul Damani et al reported a case of Orbital myocysticercosis treated medically with success ${ }^{6}$.

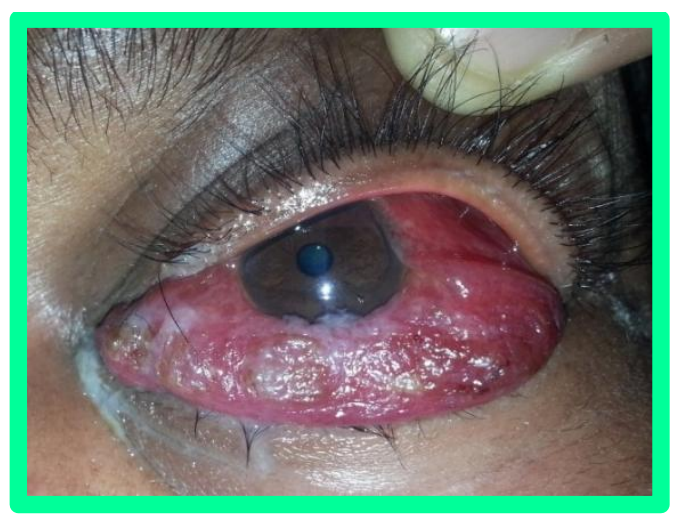

Figure 2: Ptosis, Proptosis, Chemosis and restriction in elevation

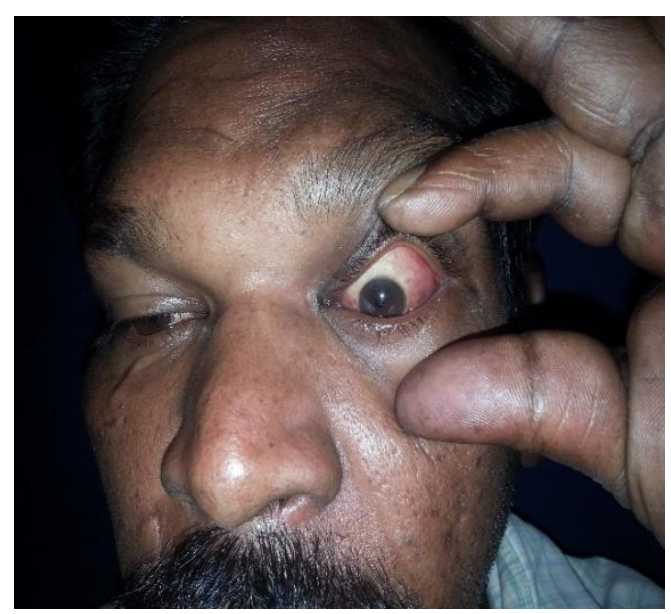

Figure 3: Reduction in Ptosis, Proptosis and Chemosis 3 weeks after Medical treatment

\section{CONCLUSION:}

It is concluded that extra Ocular and Orbital Cysticercosis can be successfully treated by Albendazole and Prednisolone. Surgery can be avoided in these cases.

Note: Financial interest nil. We acknowledge the co-operation of our patients who participated in the study.

\section{REFERENCES:}

1. Text book of parasitology by K D Chaterjee,CBS publishers, $13^{\text {th }}$ edition 2009,pages 154-155

2. Murthy GR et al Sub conjunctival cysticercosis, Indian journal of Ophthalmology, July 1986,28(2) 77-78

3. Rath $\mathrm{S}$ et al Orbital cercosis, Ophthalmology,March 2010,117(3) 600-605

4. R.Shihota, Honavar et al Management of Extra ocular Cysticercosis, BJO Aug. 1994,78(8) 621-623

5. Puri p, Grover AK et al Medical management of Myocysticercosis, Eye(London)1998, 12 (pt5) 795-799

6. MehulDamani et al a case report, Saudi journal of Ophthalmology Oct-Dec 2012 Vol 26(4), 457-45. 